\title{
A Regenerative Endodontic Approach in Mature Ferret Teeth Using Rodent Preameloblast-conditioned Medium
}

\author{
CRISTINA BUCCHI ${ }^{1,2}$, ÁLVARO GIMENO-SANDIG ${ }^{3}$, IVÁN VALDIVIA-GANDUR ${ }^{4}$, \\ CRISTINA MANZANARES-CÉSPEDES ${ }^{1}$ and JOSEP MARIA DE ANTA ${ }^{1}$ \\ ${ }^{1}$ Human Anatomy and Embryology Unit, Department of Pathology and Experimental Therapy, \\ Faculty of Medicine and Health Sciences, Bellvitge Health Science Campus, University of Barcelona, Barcelona, Spain; \\ ${ }^{2}$ Department of Integral Adult Dentistry, CICO Research Centre, University of La Frontera, Temuco, Chile; \\ ${ }^{3}$ Biotherium Bellvitge Health Science Campus, Scientific and Technological Centers, \\ University of Barcelona, Barcelona, Spain; \\ ${ }^{4}$ Biomedical Department and Dentistry Department, University of Antofagasta, Antofagasta, Chile
}

\begin{abstract}
Background: This study evaluated the effectiveness of a regenerative endodontic approach to regenerate the pulp tissue in mature teeth of ferret. The presence of odontoblastlike cells in the newly-formed tissue of teeth treated with or without preameloblast-conditioned medium was evaluated based on morphological criteria. Materials and Methods: Twenty-four canines from six ferrets were treated. The pulp was removed, and the apical foramen was enlarged. After inducing the formation of a blood clot, a collagen sponge with or without preameloblast-conditioned medium was placed underneath the cementoenamel junction. The samples were analyzed at the eighth week of follow-up. Results: Vascularized connective tissue was observed in 50\% of teeth, without differences between groups. The tissue occupied the apical third of the root canals. Odontoblast-like cells were not observed in any group. Conclusion: Revitalization of mature teeth is possible, at least in the apical third of the root canal. Further experimental research is needed to produce more reliable outcomes.
\end{abstract}

Preclinical and clinical research aimed to regenerate the pulp tissue necrotic teeth has substantially increased during the past decade (1). The main objective of regenerative endodontics is to replace damaged structures, including dentin and root structures, as well as cells of the pulp-dentin complex (2).

This article is freely accessible online.

Correspondence to: Josep Maria de Anta, Department of Pathology and Experimental Therapy, University of Barcelona, Feixa Llarga s/n, 08907, Barcelona, Spain. E-mail: janta@ub.edu

Key Words: Regenerative endodontics, revitalization, mature teeth, ferrets, pulp regeneration.
This therapy has been studied mainly for treating immature necrotic teeth, as an attempt to complete the development of the fragile dentin walls and revitalize the tooth.

In clinical practice, most cases of pulp necrosis are found in mature teeth. However, studies oriented to regenerate or repair pulp tissue of mature teeth are today scarce, most of them published in recent years (3-7). Currently, the most reliable option for the treatment of necrotic mature teeth is still root canal treatment. However, endodontically treated teeth are susceptible to reinfection and fracture, and the failure rate is close to $25 \%$ at 3-5 years (8). Moreover, endodontically treated teeth will remain devitalized throughout the patient's lifetime and therefore defenseless to new caries lesions, as the absence of pulp implies the lack of tooth defense mechanisms $(9,10)$. Therefore, teeth revitalization offers several advantages over conventional root canal treatment, such as the recovery of the natural immune system and a structurally more resistant tooth $(8,11,12)$.

There are two main limitations to treating permanent mature teeth with a regenerative endodontic approach. One is the small diameter of the apical foramen (13), which acts as a physical barrier hindering new tissue ingrowth into the root canal; and the second is the absence of an apical papilla. Immature permanent teeth present an apical papilla, which is a reservoir for mesenchymal stem cells (14). Stem cells from the apical papilla (SCAPs) have odontoblast-like differentiation potential, and produce dentin in vitro and in vivo, being responsible for root maturation (15). However, a previous study showed that even though the apical papilla is no longer present in mature teeth, an evoked-bleeding technique in these teeth is able to deliver mesenchymal stem cells from the periapical tissues (16). These cells also express mesenchymal stem cell markers, similarly to SCAPs (16).

Although these mesenchymal stem cells have odontogenic potential $(15,17)$, once in the root canal, they seem to 
Table I. Summary of histological findings found in the intracanal and periapical tissues two months after treatment.

\begin{tabular}{lcc}
\hline Parameter & Control group (n=11), $\mathrm{n}(\%)$ & Experimental group (n=11), $\mathrm{n}(\%)$ \\
\hline Presence of newly formed iCT & $4(36.36 \%)$ & $7(63.63 \%)$ \\
Apical third & $4(100 \%)$ & $7(100 \%)$ \\
Medium third & $0(0 \%)$ & $0(0 \%)$ \\
Coronal third & $0(0 \%)$ & $0(0 \%)$ \\
Presence of inflammatory infiltrate in the iCT (percentage of teeth with iCT) & $2(50 \%)$ & $4(57.14 \%)$ \\
Presence of inflammatory infiltrate in the periapical tissues & $6(54.54 \%)$ & $7(63.63 \%)$ \\
Debris from biomechanical preparation & $9(81.81 \%)$ & $6(54.54 \%)$ \\
Apical cementum remodeling & $8(72.72 \%)$ & $9(81.81 \%)$ \\
Dentin resorption & $0(0 \%)$ & $1(9.4 \%)$ \\
Presence of intracanal hard tissue (cementum-like tissue) & $2(18.8 \%)$ & $2(18.8 \%)$ \\
Presence of Sharpey's fibers in the intracanal space & $2(18.8 \%)$ & $1(9.4 \%)$ \\
\hline
\end{tabular}

iCT: Intracanal connective tissue.

differentiate into cementoblast-like cells and osteoblast-like cells, both in mature and immature teeth (18). This might suggest that these cells do not receive the correct signals necessary to promote odontoblast-like differentiation.

During tooth embryogenesis, the inner enamel epithelium and the underlying mesenchyme participate in a mutual interaction by secreting growth factors that induce their differentiation into ameloblasts and odontoblasts, respectively (19). Previous studies have identified 71 factors in the conditioned medium (CM) from preameloblasts (20). These molecules participate in cellular transduction, cell growth, transcription and metabolism and may act as attractants of bioactive signaling molecules required to induce differentiation of mesenchymal stem cells into odontoblastlike cells. An in vitro study has shown that preameloblast$\mathrm{CM}$ induces odontoblast-like differentiation of mesenchymal stem cells (20). Moreover, an in vivo study in immature teeth claimed that newly formed dentin-like and pulp-like tissues were more frequently observed in CM-treated teeth (21).

Taking into account these data, our objectives were the following: Firstly, to evaluate the effectiveness of a regenerative endodontic approach to regenerating the pulp tissue of mature teeth of ferrets after pulpectomy; secondly, to evaluate the presence of odontoblast-like cells in the newly-formed tissue of teeth treated with and without preameloblast-CM; and thirdly, to analyze the suitability of the ferret as an animal model for regenerative endodontics.

\section{Materials and Methods}

This study was approved by the Ethical Committee for Animal Experimentation of the University of Barcelona, Spain (no. 519116). All animal experiments were conducted using the EU Directive 2010/63/EU for animal experiments and the Guiding Principles in the Care and Use of Animals approved by the Council of the American Physiological Society.
Preameloblast-CM. Apical bud cells (ABCs) from Sprague-Dawley rats were isolated and cultured as previously described (22). The handling of $\mathrm{ABCs}$ was performed inside a laminar flow hood with sterile instruments. Briefly, 20 apical bud tissues of lower incisors of 4-day postnatal rats were collected. The $\mathrm{ABCs}$ were enzymatically isolated with type I collagenase $(0.62 \mathrm{mg} / \mathrm{ml}$; Sigma, St. Louis, MO, USA) for $30 \mathrm{~min}$, and collected by centrifugation. Cells were cultured in $10 \mathrm{~mm}$ Petri dishes in Dulbecco's modified Eagle's medium (DMEM; Gibco BRL, Carlsbad, CA, USA) with 10\% inactivated fetal bovine serum (FBS) and 1\% antibiotics (penicillin/streptomycin) and $2.5 \mathrm{mg} / \mathrm{ml}$ ascorbic acid, under $5 \%$ carbon dioxide at $37^{\circ} \mathrm{C}$, until confluence. After differential repeated trypsinization $(0.25 \%$ trypsin/EDTA), cells were seeded onto 6-well plates in keratinocytefree medium (Gibco BRL) with $0.01 \mathrm{ng} / \mathrm{ml}$ epidermal growth factor and $25 \mu \mathrm{m} / \mathrm{ml}$ of bovine pituitary extract until confluence (Invitrogen Corp., Carlsbad, CA, USA). Cells were then washed twice with PBS and cultured with DMEM without FBS. After 24 hours, supernatants were collected and filtered using sterile $0.22-\mu \mathrm{m}$ diameter pore size membranes, aliquoted and stored at $-20^{\circ} \mathrm{C}$.

Ferret model. Six 4- to 6-month-old male and female ferrets (Mustela putorius furo) were commercially acquired (Isoquimen, Sant Feliu de Codines, Catalunya, Spain) and used in this study. Periapical radiography of the teeth showed complete root development. The four canine teeth from each ferret were treated and randomly assigned to the control $(n=12)$ or the experimental group $(n=12)$; randomization was performed with a coin. In order to study the normal histology of pulp tissue, four untreated molars were also analyzed (negative controls). Ferrets were deprived of food for $12 \mathrm{~h}$ before surgical intervention. Dental surgeries were performed at the Biotherium of the University of Barcelona (UEA de Bellvitge B9900046), in the morning of 6 working days, under general anesthesia ( $25 \mathrm{mg} / \mathrm{kg}$ ketamine and $2 \mathrm{mg} / \mathrm{kg}$ xylazine) and analgesia (1 $\mathrm{mg} / \mathrm{kg}$ meloxicam). The clinical protocol was as follows:

Teeth crowns were disinfected with $2 \%$ chlorhexidine. Treatment was carried out under local anesthesia (Mepivacaine $\mathrm{HCl} \mathrm{3 \%}$; Septodont, Lancaster, PA, USA) and endodontic access was performed using a high-speed hand piece under constant irrigation with saline. Pulp was removed with a \#15 sterile stainless-steel endodontic hand file (Dentsply Maillefer, Ballaigues, Switzerland) and working length was determined 
using a portable digital X-ray device (iRay D4, Dexcowin, Los Angeles, CA, USA). The apical cemental barrier was penetrated with \#15 K-file and root canals were prepared $0.5 \mathrm{~mm}$ beyond the canal terminus. The root canals were prepared and the apical foramen was enlarged using a \#80 K-file (Dentsply Maillefer, Ballaigues, Switzerland) with $2 \%$ sodium hypochlorite (23). Root canals were rinsed with 17\% EDTA and sterile saline and dried with paper points. A sterile \#15 K-file was inserted $2 \mathrm{~mm}$ beyond the canal terminus to irritate the periapical tissues and induce bleeding and the formation of a blood clot inside the root canal. A hemostatic absorbable lyophilized collagen sponge (Hemospon; Technew, Rio de Janeiro, RJ, Brazil) was placed over the blood clot. The collagen sponge was cut to a size slightly superior to the coronal part of the root canal, and then submerged in DMEM (control group) or preameloblast-CM (experimental group). Teeth were sealed with grey MTA (CHL Medical Solutions, Milan, Lombardy, Italy), flowable resin composite (CHL Medical Solutions) and amalgam (Bestdent, Montebello, Vicenza, Italy).

After completing the surgical procedures, animals were given supportive analgesics for 3 days ( $1 \mathrm{mg} / \mathrm{kg}$ meloxicam). A special soft diet was not needed. Ferrets were given ad libitum access to food and water, kept under a 12-h light/12-h dark cycle with three animals per cage. Eight weeks after surgery, animals were sacrificed using an anesthetic overdose ( $200 \mathrm{mg} / \mathrm{kg}$ pentobarbital).

Jaws and maxillaries including the treated teeth were sectioned and immediately submerged in $10 \%$ formalin for 24 hours. Using a diamond burr, a small cavity was created in the crown of the canines to ensure intracanal tissue fixation.

Each mandible/maxilla was scanned in a micro-computed tomographic (CT) device (Quantum FX microCT; PerkinElmer, Waltham, MA, USA). Briefly, the samples were scanned at $90 \mathrm{kV}$ and $160 \mathrm{~mA}$ through a $20 \mathrm{~mm}$ FOV using an exposure time of 4.5 $\min$. The acquired images were reconstructed into cross-sectional slices using PerkinElmer software (PerkinElmer, Health Sciences) by the Feldkamp method. The reconstructed image stacks of the bone blocks were co-registered using OsiriX DICOM Viewer v. 9.0 software (Pixmeo DARL, Geneva, Switzerland) for threedimensional visualization.

Histological processing. All samples were decalcified using a solution containing $14.28 \%$ EDTA and 5\% formic acid for approximately 3 weeks. The samples were then processed with a tissue processor (Shandon Citadel 1000; Thermo Scientific, Waltham, MA, USA), dehydrated through ascending gradations of ethanol in the following manner: one cycle of $70 \%$ ethanol $(8 \mathrm{~h})$, one cycle of $90 \%$ ethanol $(8$ h), three cycles of $100 \%$ ethanol $(8,16$ and $14 \mathrm{~h})$, three cycles of xylene $(5,5$ and $6 \mathrm{~h})$, and two cycles of paraffin ( 6 and $16 \mathrm{~h})$.

Samples were sectioned using a Leica Jung RM2045 microtome (Leica, Nussloch, Baden-Württemberg, Germany). Longitudinal sections of $5 \mu \mathrm{m}$ through the root apical foramen were obtained and placed on poly-L-lysine-coated glass slides. Tissues were stained with hematoxylin and eosin (H-E), and toluidine blue, and evaluated under light microscopy (Olympus CH30; Olympus, Tokyo, Japan). Histological analysis was performed by two histologists blinded to the experimental groups. Histological characteristics of the newly formed tissues were performed using morphological criteria and scored according to the histopathological parameters reported by Gomes-Filho et al. (24).

Statistical analysis. The categorical data (presence/absence of cementum-like or dentin-like tissues/inflammatory cells, fibroblast, odontoblast-like cells) were analyzed using a Fischer's exact test, with a significance level of $p<0.05$.

\section{Results}

Due to the lack of blood clot formation and to fracture of the file in the root canal, one control and one experimental tooth were excluded, respectively. Thus, 11 teeth (from six ferrets) per group were analyzed. No periapical lesions in any teeth were radiographically observed.

Histological analysis: Control and experimental group. Newly formed intracanal connective tissue (iCT) was observed in $50 \%$ of the teeth, without statistical differences between groups (Table I) $(p>0.05)$. Intracanal tissue was characterized as non-organized loose connective tissue with a low to moderate number of blood vessels, localized in the central region of the canal (Figures 1 and $2 \mathrm{~A}$ and B). However, the iCT only occupied the apical third of the root canal. Cells were mostly fibroblasts (Figure 1B, D and F) and odontoblast-like cells were not observed in any group. Root canals without iCT were observed as being mostly empty and with some chronic inflammatory infiltrate and debris from biomechanical instrumentation (Figure 2C and D).

Acute inflammatory cells in the intracanal tissue were observed in $50 \%$ and $57 \%$ of control and experimental groups, respectively (Figure 1C, E and F and Figure 2C), without statistical differences between groups $(p>0.05)$. In the experimental group, dentin resorption in the apical third of one tooth was observed (Figure 2D).

Cementum-like tissue was observed in four teeth, both attached to the wall canals as well as free in the iCT (Figure 1A-D).

Scarce inflammatory cells in the periapical area of most teeth of both groups were present (Table I) (Figure 2D). Cementum remodeling at the apical portion of most teeth was also observed (Table I) (Figure 2B).

Normal histology of mature teeth from ferrets (negative control group). The normal histology of mature teeth from the ferrets can be seen in Figure 3. Pulp was observed as an organized, mature and vascularized tissue (Figure 3A and B), with odontoblasts arranged in a pseudostratified palisade (Figure 3B), compatible with a mature although young pulp tissue. Dentin was observed with ordered dentinal tubuli and predentin (Figure 3B). The maturation of the root is evident. Teeth presented a small apical foramen and cellular cementum at the apical area (Figure 3A).

Ferret as an animal model for regenerative endodontics. The mean weight of the animals was $2.8 \mathrm{~kg}$ and all animals were healthy prior to and after the surgery. No adverse events were 

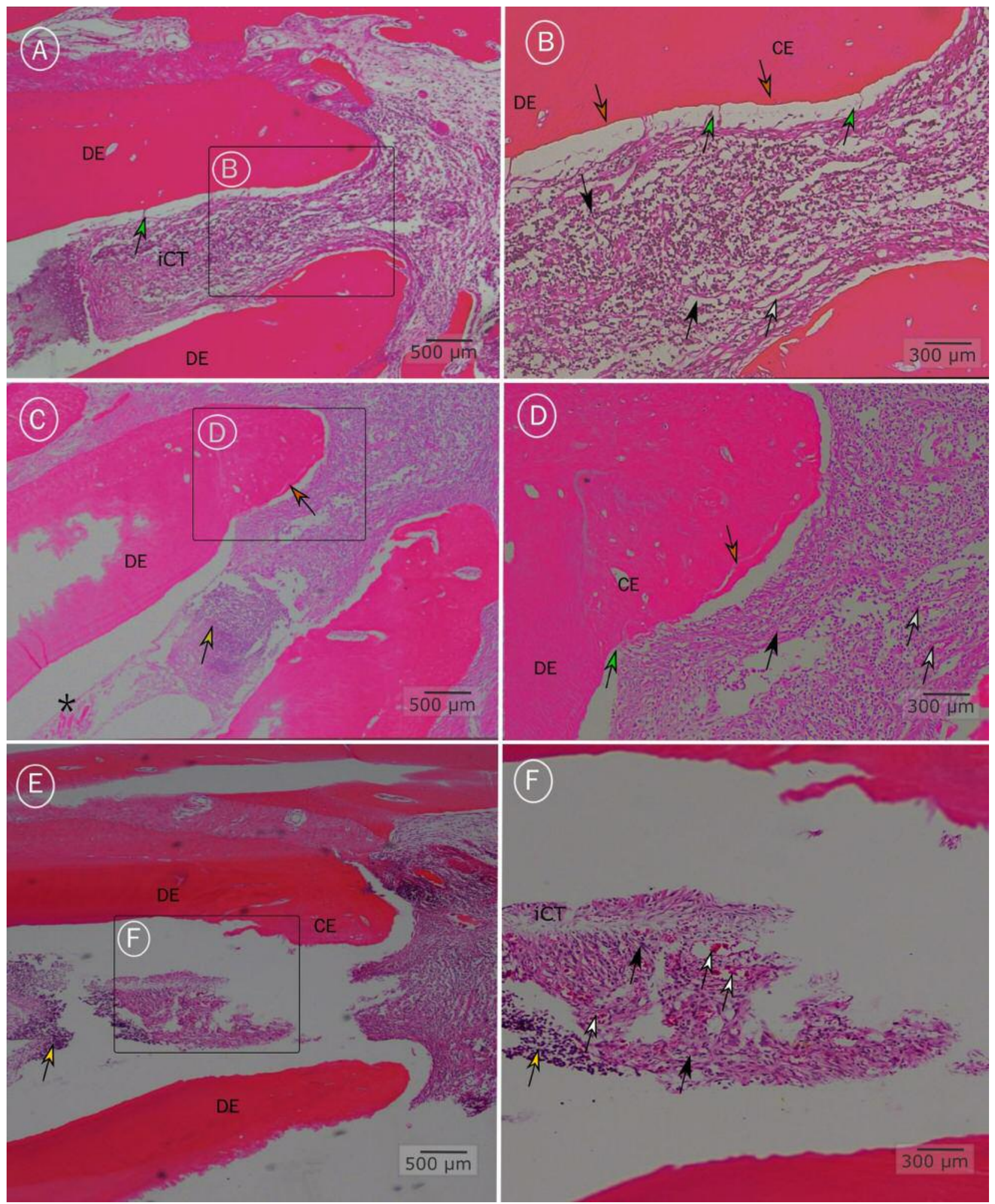

Figure 1. Histological appearance with hematoxylin-eosin staining $(H-E)$ of mature teeth treated with a regenerative endodontic approach. The intracanal connective tissue (iCT) occupied the apical third of the root canal of control $(A, B)$ and experimental $(C-F)$ teeth. A large number of fibroblasts (black arrows), inflammatory cells (yellow arrows) and a moderate number of blood vessels (white arrows) were observed (A-D). Intracanal Sharpey's fibers (green arrows) $(B$ and $D$ ) and cementum-like (CE) tissue attached to the inner walls (orange arrows) were also observed. DE: Dentin. *Debris from biomechanical preparation. 


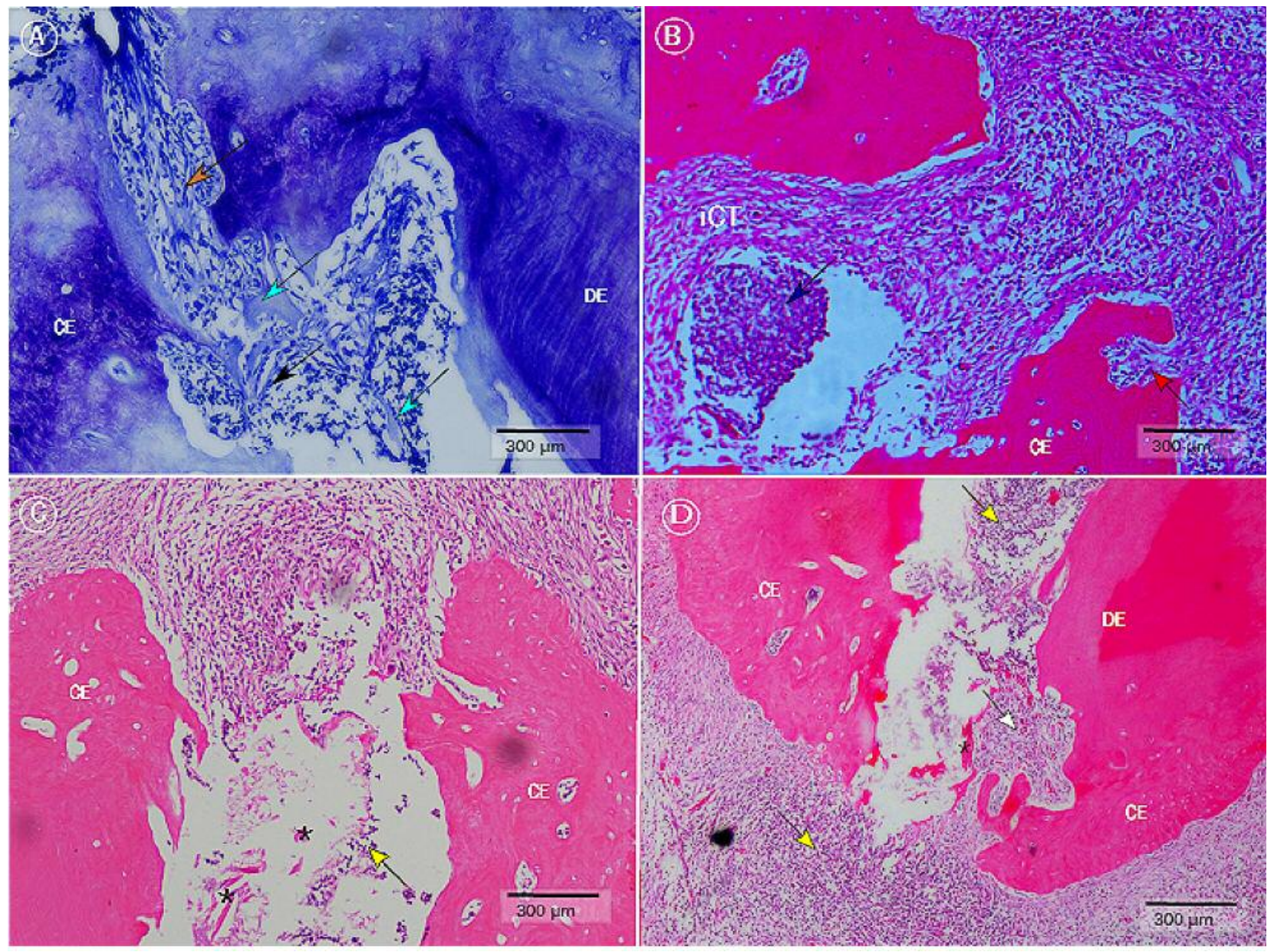

Figure 2. Histological appearance with toluidine blue $(A)$ and $H-E(B-D)$ staining of mature teeth in the control group treated with the regenerative endodontic approach. The apical delta and accessory canals (brown arrow) were observed (A). A lack of intracanal connective tissue (iCT) was observed in most samples of the control group ( $C$ and D). Fibroblasts (black arrows), inflammatory cells (yellow arrows), necrotic tissue (blue arrow) were observed in samples with iCT (A and B). Islets of cementum like tissue (CE) (A) (light blue arrow) were also observed. Cementum $(C E)(B)$ and dentin $(D E)(D)$ resorption were observed in some samples (red arrows) $(D)$, as well as debris from biomechanical preparation $(*)$ $(C$ and $D)$.

observed. Although isolation of teeth with a rubber dam was not possible, the size of ferret canine teeth was adequate to prepare the canals using wide files (\#80), irrigation and placement of restorative materials without major complications (Figure 4A-C). The size of the mouth also allowed intraoral radiographs to be taken. The dimension of incisors, however, was too small to perform endodontic experiments (approximately $1 \mathrm{~mm}$ width $\times 2 \mathrm{~mm}$ height) (Figure 4B). Periapical radiographs and clinical examination revealed a pronounced curvature of the canine teeth, especially of mandibular teeth. Thus, instrumentation with flexible files is highly recommended. In the micro-CT analysis, canine teeth presented characteristic apical delta, with several accessory canals (Figure 2A and 4D), which may explain the clinical difficulties encountered in reach the working length.

\section{Discussion}

In our study, $50 \%$ of teeth showed some degree of vascularized connective tissue at the intracanal space. However, it occupied only the apical third of the canal. Moreover, the neo-formed tissue was disorganized and did not have the characteristic layers of mature pulp.

In this study preameloblast-CM was used to simulate the cellular and molecular conditions occurring during tooth embryogenesis between the inner enamel epithelium and the underlying mesenchyme. These tissues participate in a mutual interaction by secreting growth factors that induce their respective differentiation into ameloblasts and odontoblasts (19). Therefore, we hypothesized that growth factors present in the CM from preameloblasts (20) would 

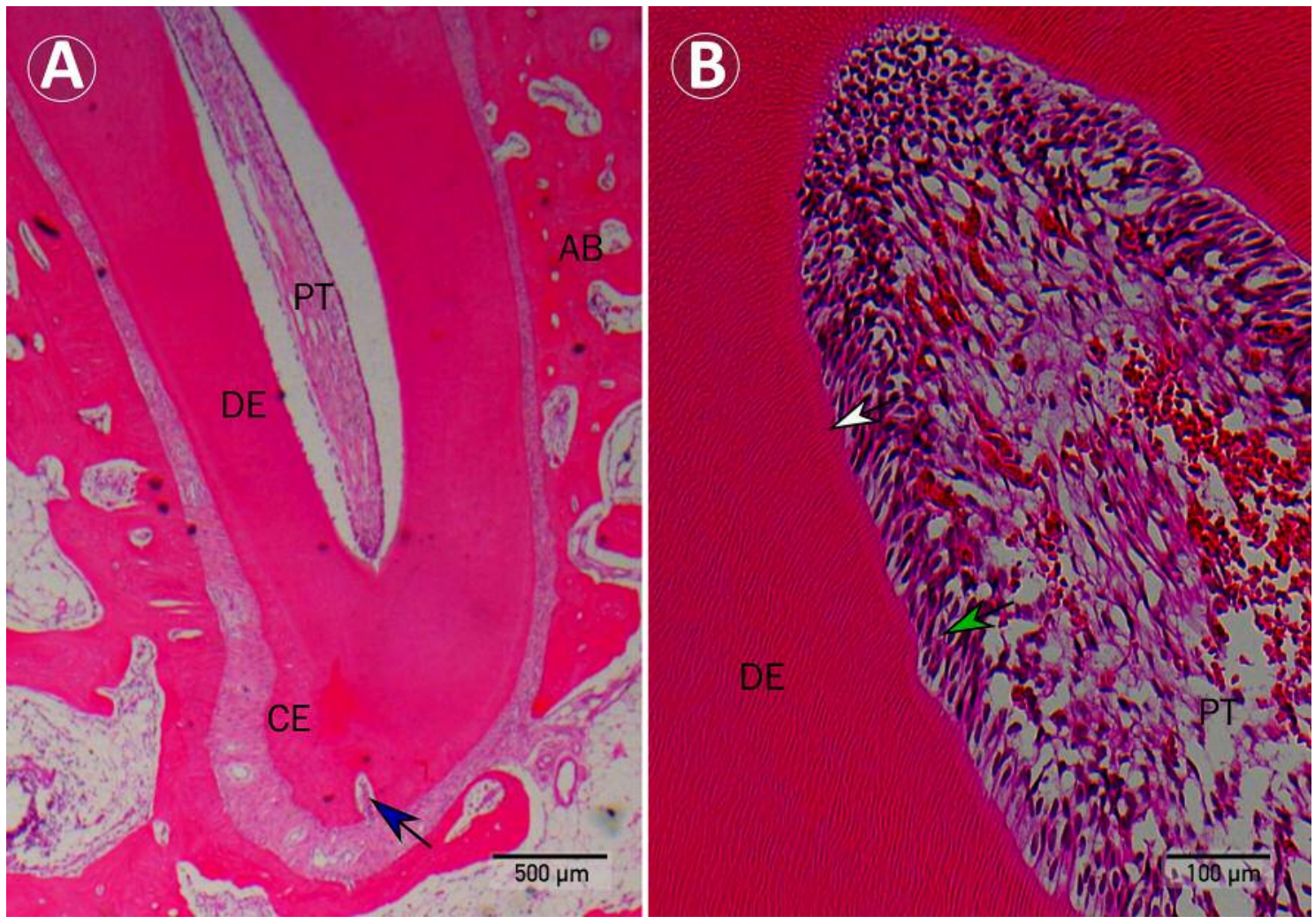

Figure 3. Normal histology (H-E) of ferret non-treated molars in longitudinal (A) and transversal (B) views. DE: Dentin; CE: cementum; PT: pulp tissue; AB: alveolar bone; blue arrow: apical foramen; green arrow: odontoblasts arranged in a pseudrostratified palisade; white arrow: predentin .

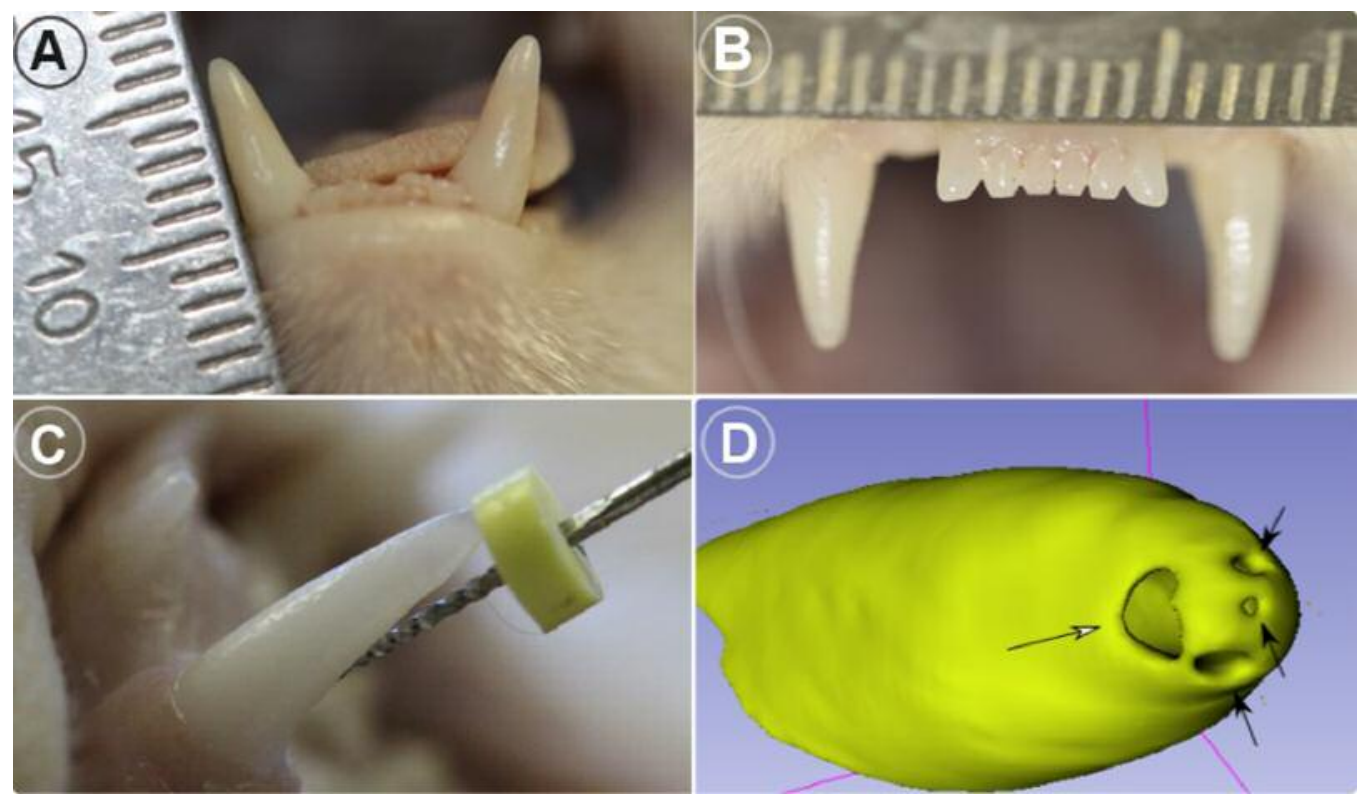

Figure 4. A: Canine crown of $6 \mathrm{~mm}$ in height. B: Maxillary incisors, dimension $1 \times 2 \mathrm{~mm}$. C: Canal preparation with file \#20 after creating the coronal access of a maxillary canine. D: Three-dimensional reconstruction of the apical third of a ferret canine tooth. Three accessory foramens (black arrows) and one enlarged apical foramen (white arrow) can be observed. 
induce the differentiation of mesenchymal stem cells into odontoblast-like cells, as previously reported in in vitro studies $(20,21)$.

Several attempts at treating immature teeth with a regenerative endodontic approach have been made. With few articles reporting success until date (12), these attempts tried to induce differentiation of SCAPs and dental pulp stem cells into odontoblast-like cells in vivo $(18,25)$. In mature teeth, the induction of intracanal bleeding attract mesenchymal stem cells from the periapical tissues (16). The differentiation process of stem cells after revascularization procedures always leads to cementoblastic or osteoblastic lineage formation instead of generating odontoblast-like cells. Hence, this leads to the formation of cementum or bone-like tissues instead of dentin $(18,24-26)$. In this sense even with the use of preameloblast-CM, the results of our study confirm those previously published. Only periodontal tissues (cementum-like and Sharpey's fibers) were observed.

The size of the apical foramen seems to be a major concern in pulp repair of mature teeth, since a small apical foramen diameter might be a physical limitation for the ingrowth of new tissue inside the root canal. Although some studies refuted the influence of the apical diameter on clinical outcomes (27), others showed that an apical foramen diameter of $<1 \mathrm{~mm}$ exhibited a greater increase in root thickness, length, and apical narrowing (28). To date, there is no established standard size of apical foramen required to ensure new tissue ingrowth into the root canal. In the present study, canal preparation was made using a \#80 file $0.5 \mathrm{~mm}$ beyond canal terminus to ensure the widening of the foramen (13). However, the achieved size might not have been enough to allow new tissue ingrowth, that might explain why only $50 \%$ of the teeth presented vital intracanal connective tissue. Therefore, it is necessary to determine the diameter at which the apical foramen should be enlarged in order to arrive at more predictable outcomes when treating mature teeth with a regenerative approach. Moreover, the method for enlargement should also be properly studied since the effect of instrumentation over the apical constriction may also explain the inflammatory response of the periapical tissues, as well as the reaction of the apical cementum, which showed zones of remodeling. In summary it is necessary to establish a standardized clinical protocol for regenerative endodontics in mature teeth, as already exists for immature teeth (23), since the characteristics of mature teeth (a closed apex and the absence of apical papilla) deserve special consideration.

This study confirms the utility of ferrets as a model for regenerative endodontics, as previously proposed (29). Ferrets are easy to handle $(2-3 \mathrm{~kg})$, and their mouths and teeth are large enough to perform the clinical procedures for this therapy, although not to perform isolation with a rubber dam. It is also necessary to consider the apical delta and the pronounced curvature of the mandibular canines when planning a treatment.

\section{Conclusion}

Revascularization of mature teeth is possible, at least in the apical third of the root canal. However, further research in animal models is needed to create quicker and more reliable regenerative endodontic procedures that can be evaluated in clinical trials.

\section{Conflicts of Interest}

The Authors declare that no conflicts of interest exist regarding this study.

\section{Authors' Contributions}

$\mathrm{CB}$, AGS and CMC planned the study; CB, AGS and JMA performed the animal experiments; $\mathrm{CB}$ and IVG processed the samples and did the histological analysis; $\mathrm{CB}$ researched and wrote the article; CMC, IVG and JMA offered scientific advice and proofread the article. All Authors read and approved the manuscript.

\section{Acknowledgements}

The Authors thank Eva Sanchez for her assistance in the histological processing of the samples and Dr. Bernardo Venegas for his assistance with the histological characterization of the samples.

This study was economically supported $80 \%$ by the Faculty of Dentistry of the University of Barcelona and $20 \%$ by MINEDUCUA project, code ANT 1755.

\section{References}

1 Kontakiotis EG, Filippatos CG, Tzanetakis GN and Agrafioti A: Regenerative endodontic therapy: A data analysis of clinical protocols J Endod 41(2): 146-154, 2015. PMID: 25301351. DOI: 10.1016/j.joen.2014.08.003

2 Murray PE, Garcia-Godoy F and Hargreaves KM: Regenerative endodontics: A review of current status and a call for action. J Endod 33(4): 377-390, 2007. PMID: 17368324. DOI: 10.1016/ j.joen.2006.09.013

3 Nageh M, Ahmed GM and El-Baz AA: Assessment of regaining pulp sensibility in mature necrotic teeth using a modified revascularization technique with platelet-rich fibrin: A clinical study. J Endod 44(10): 1526-1533, 2018. PMID: 30174103. DOI: $10.1016 /$ j.joen.2018.06.014

4 Paryani K and Kim SG: Regenerative endodontic treatment of permanent teeth after completion of root development: A report of 2 cases. J Endod 39(7): 929-934, 2013. PMID: 23791266. DOI: $10.1016 /$ j.joen.2013.04.029

5 Laureys WGM, Cuvelier CA, Dermaut LR and De Pauw GAM: The critical apical diameter to obtain regeneration of the pulp tissue after tooth transplantation, replantation, or regenerative endodontic treatment. J Endod 39(6): 759-763, 2013. PMID: 23683275. DOI: 10.1016/j.joen.2013.02.004

6 Saoud TM, Martin G, Chen YHM, Chen KL, Chen CA, Songtrakul K, Malek M, Sigurdsson A and Lin LM: Treatment of mature permanent teeth with necrotic pulps and apical periodontitis using regenerative endodontic procedures: A case 
series. J Endod 42(1): 57-65, 2016. PMID: 26525552. DOI: 10.1016/j.joen.2015.09.015

7 Nagas E, Uyanik MO and Cehreli ZC: Revitalization of necrotic mature permanent incisors with apical periodontitis: A case report. Restor Dent Endod 43: e31, 2018. PMID: 30135850 . DOI: $10.5395 /$ rde.2018.43.e31

8 He L, Kim SG, Gong Q, Zhong J, Wang S, Zhou X, Ye L, Ling $\mathrm{J}$ and Mao JJ: Regenerative endodontics for adult patients. J Endod 43(9): S57-64, 2017. PMID: 28844305. DOI: 10.1016/ j.joen.2017.06.012

9 Couve E, Osorio $\mathrm{R}$ and Schmachtenberg O: The amazing odontoblast: Activity, autophagy, and aging. J Dent Res 92(9): 765772, 2013. PMID: 23803461. DOI: $10.1177 / 0022034513495874$

10 Couve E, Osorio $\mathrm{R}$ and Schmachtenberg O: Reactionary dentinogenesis and neuroimmune response in dental caries. J Dent Res 93(8): 788-793, 2014. PMID: 24928097. DOI: $10.1177 / 0022034514539507$

11 Sedgley CM and Messer HH: Are endodontically treated teeth more brittle? J Endod 18(7): 332-335, 1992. PMID: 1402595. DOI: $10.1016 / \mathrm{S} 0099-2399(06) 80483-8$

12 Austah O, Joon R, Fath WM, Chrepa V, Diogenes A, Ezeldeen M, Couve E and Ruparel NB: Comprehensive characterization of 2 immature teeth treated with regenerative endodontic procedures. J Endod 44(12): 1802-1811, 2018. PMID: 30477666. DOI: $10.1016 /$ j.joen.2018.09.007

13 Bucchi C, Gimeno-Sandig A, Manzanares-Céspedes C: Enlargement of the apical foramen of mature teeth by instrumentation and apicoectomy. A study of effectiveness and the formation of dentinal cracks. Acta Odontol Scand 75(7): 488-495, 2017. PMID: 28678588. DOI: 10.1080/00016357.2017. 1344877

14 Huang GTJ, Sonoyama W, Liu Y, Liu H, Wang S and Shi S: The hidden treasure in apical papilla: The potential role in pulp/dentin regeneration and bioroot engineering. J Endod 34(6): 645-651, 2008. PMID: 18498881. DOI: 10.1016/j.joen.2008.03.001

15 Sonoyama W, Liu Y, Yamaza,T, Tuan RS, Wang S, Shi S and Huang HT: Characterization of apical papilla and its residing stem cells from human immature permanent teeth. A pilot study. J Endod 34(2): 166-171, 2008. PMID: 18215674. DOI: 10.1016/ j.joen.2007.11.021

16 Chrepa V, Henry MA, Daniel BJ and Diogenes A: Delivery of apical mesenchymal stem cells into root canals of mature teeth. J Dent Res 94(12): 1653-1659, 2015. PMID: 26195498. DOI: $10.1177 / 0022034515596527$

17 Oh H-J, Choung H-W, Lee H-K, Park S-J, Lee J-H, Lee D-S, Seo BM and Park JC: CPNE7, a preameloblast-derived factor, regulates odontoblastic differentiation of mesenchymal stem cells. Biomaterials 37: 208-217, 2015. PMID: 25453951. DOI: 10.1016/j.biomaterials.2014.10.016

18 Del Fabbro M, Lolato A, Bucchi C, Taschieri S and Weinstein RL: Autologous platelet concentrates for pulp and dentin regeneration: A literature review of animal studies. J Endod 42(2): 250-257, 2016. PMID: 26631301. DOI: 10.1016/ j.joen.2015.10.012

19 Balic A and Thesleff I: Tissue interactions regulating tooth development and renewal. Curr Top Dev Biol 115: 157-186, 2015. PMID: 26589925. DOI: 10.1016/bs.ctdb.2015.07.006
20 Lee JH, Lee DS, Choung HW, Shon WJ, Seo BM, Lee EH, Cho JY and Park JC: Odontogenic differentiation of human dental pulp stem cells induced by preameloblast-derived factors. Biomaterials 32(36): 9696-9706, 2011. PMID: 21925730. DOI: 10.1016/j.biomaterials.2011.09.007

21 Yoo YJ, Lee W, Cho YA, Park JC, Shon WJ and Baek SH: Effect of conditioned medium from preameloblasts on regenerative cellular differentiation of the immature teeth with necrotic pulp and apical periodontitis. J Endod 40(9): 1355-1361, 2014. PMID: 25146015. DOI: 10.1016/j.joen.2014.02.009

22 Fang J, Tang L, Liu X, Wen L and Jin Y: Changes of the unique odontogenic properties of rat apical bud cells under the developing apical complex microenvironment. Int $\mathbf{J}$ Oral Sci 1(1): 26-33, 2009. PMID: 20690501. DOI: 10.4248/ijos.08017

23 Galler KM, Krastl G, Simon S, Van Gorp G, Meschi N, Vahedi B and Lambrechts P: European Society of Endodontology position statement: Revitalization procedures. Int Endod J 49(8): 717-723, 2016. PMID: 26990236. DOI: 10.1111/iej.12629

24 Gomes-Filho JE, Tobias Duarte PC, Ervolino E, Mogami Bomfim SR, Xavier Abimussi CJ, Mota Da Silva Santos L, Lodi CS, Penha De Oliveira SH, Dezan E Jr. and Cintra LT: Histologic characterization of engineered tissues in the canal space of closed-apex teeth with apical periodontitis. J Endod 39(12): 1549-1556, 2013. PMID: 24238445. DOI: 10.1016/ j.joen.2013.08.023

25 Zhu X, Wang Y, Liu Y, Huang GT-J and Zhang C: Immunohistochemical and histochemical analysis of newly formed tissues in root canal space transplanted with dental pulp stem cells plus platelet-rich plasma. J Endod 40(10): 1573-1578, 2014. PMID: 25260728. DOI: 10.1016/j.joen.2014.05.010

26 Zhou R, Wang Y, Chen Y, Chen S, Lyu H, Cai Z and Huang X: Radiographic, histologic, and biomechanical evaluation of combined application of platelet-rich fibrin with blood clot in regenerative endodontics. J Endod 43(12): 2034-2040, 2017. PMID: 29032818. DOI: 10.1016/j.joen.2017.07.021

27 Fang Y, Wang X, Zhu J, Su C, Yang Y and Meng L: Influence of apical diameter on the outcome of regenerative endodontic treatment in teeth with pulp necrosis: A review. J Endod 44(3): 414-431, 2018. PMID: 29273495. DOI: 10.1016/j.joen.2017. 10.007

28 Estefan BS, El Batouty KM, Nagy MM and Diogenes A: Influence of age and apical diameter on the success of endodontic regeneration procedures. J Endod 42(11): 1620-1625, 2016. PMID: 27623497. DOI: 10.1016/j.joen.2016.06.020

29 Torabinejad M, Corr R, Buhrley M, Wright K and Shabahang S: An animal model to study regenerative endodontics. J Endod 37(2): 197-202, 2011. PMID: 21238802. DOI: 10.1016/j.joen. 2010.10.011 